\title{
Using Performance Evaluation of Touchpad and Touchscreen
}

\author{
Punyanut Tanyakunsadcha ${ }^{+}$and Phairoat Ladavichitkul \\ Department of Industrial Engineering, Faculty of Engineering, Chulalongkorn University, Thailand
}

\begin{abstract}
Digital pen or Stylus is extensively used in multimedia design such as graphic and animation design. In business, it has been used for electronic signature. Digital pen technology can be separated by the input device as a touchscreen and a touchpad. Both input devices are different in visual perception. A touchpad is an indirect visual perception device often has a cursor lag problem that lead to lower performance than a direct visual perception device as touchscreen. Moreover, the display size is another important factor of touchpad using, a smaller display is harder to percept and control. In this research, there were two objectives which were 1. to compare the working performance between touchscreen and touchpad, and 2. to evaluated the effect of display sizes while using touchpad on working performance. There were eight participants used a digital pen to perform tapping and dragging tasks following fitts' law and steering law concepts. The results showed that the touch screen usage had a better performance than touchpad usage in both tasks. The display size of touchpad usage effected on the using performance in both tasks. The smaller display size decreased the working performances.
\end{abstract}

Keywords: touchpad, touchscreen, tapping, dragging.

\section{Introduction}

Currently, tablet computer has central role to play in the world of information and technology cause it has been applied in many activities. Direct-touch interface is an easy input method using a digital pen. Most tablets use touchscreen as their primary device. For the non-touchscreen computer, a touchpad is used as their input device. Using touchpad required display to show the pointer that may lead to the pointer lag based on the computer performance. Moreover, the viewing distance might effect on the visual performance [1]. The mean viewing distance for LCD monitor was $42.3 \mathrm{~cm}$. [2]. The minimum viewing distance was $40 \mathrm{~cm}$ $[3,4]$ and the general viewing distance was $50 \mathrm{~cm}$. [1] for touchscreen usage.

Tapping tasks is based on a robust model of human movement known as Fitts' law. Fitts' original experiments used reciprocal tapping tasks where one alternately tapped on two rectangular targets [5]. The controlled variables were target width and the distance between targets [5,6,7]. However, the motion was one dimensional [5]. Extending the model to two dimensions, which were appropriate pointing tasks in computer usage [6,7]. Steering law is applied from Fitts' law to measure dragging task performance [6]. The guideline of ISO 9241-9 specifying for requirements for non-keyboard input devices describes a performance test method for evaluating pointing task on computer interface by using Fitts' law concept to evaluate tapping task and using steering law to evaluate dragging task [8]. Fitts' law and Steering law described the relationship between movement time and Index of difficulty (ID) on human computer interaction [1,5,6,7]. The movement of pointing task according to the condition as fast as possible without any error [4]. There were many studies the effect on visual arc to identify the proper text size. Due to a small visual arc, it's hard to perceive data for user then respond slow. So object size or viewing distances influence the performance of tracking and dragging tasks. The purpose of this paper were 1. to compare the using performance between the touchpad and the touchscreen and 2. to study the effects of visual arc on touchpad using performance by increasing the distance and convert to the relative size compared to touchpad side.

\footnotetext{
+ Corresponding author. Tel.: +6680-422-0107

E-mail address: punyanut.t@ student.chula.ac.th.
} 


\section{Experiment}

\subsection{Subjects and apparatus}

Eight volunteers (four male and four female) aged 21-28 years (mean 25 years) participated in the experiment. Temperature was controlled at $25^{\circ} \mathrm{c}$ and lighting condition set up with 400 Lux. All participants were healthy and recruited from the university students. Subjects could use their eye glasses or contact lens.

Lenovo Think Pad 10 with 10.1 inches $(1280 \times 800$ pixels $)$ was used as the touchscreen and touchpad input devices (see Fig. 1a). For using as touchscreen, the distance between subject and touchscreen was set at $40 \mathrm{~cm}$. as shown in Fig. 1c). For using as touchpad, the Samsung HD Flat TV with 32 inches $(1366 \times 768$ pixels) was used as a display for tapping and dragging tasks (see Fig. 1b). The distance between subject and the display monitor was controlled as shown in Fig. 1d. These task set up parameters were fixed to all participants, who were adjusted their seating positions for their comfort.
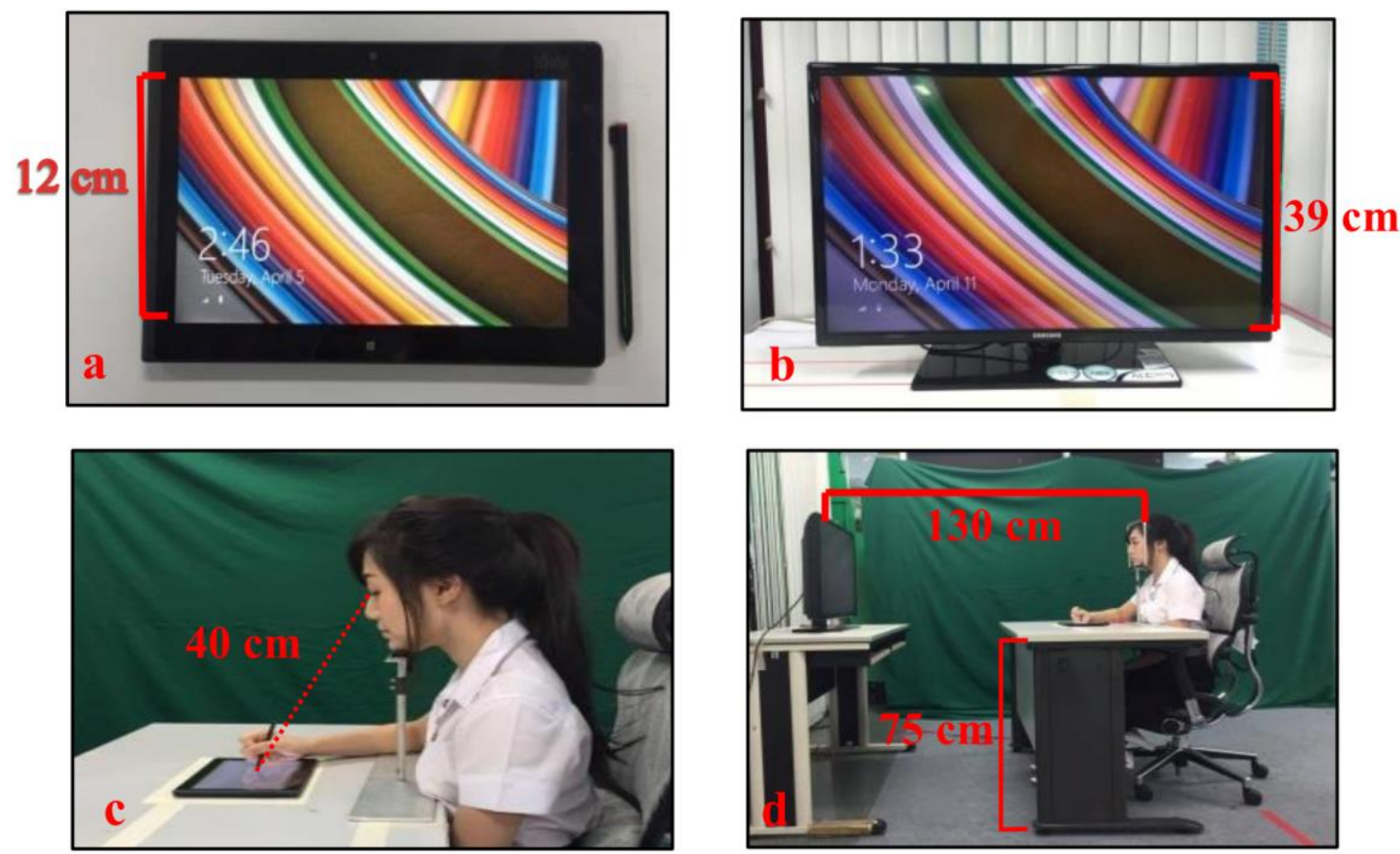

Fig. 1: (a) Tablet size. (b) Display size. (c) Distance control on touchscreen usage. (d) Distance control on touchpad usage.

\subsection{Visual arc}

Visual arc was depend on S and D can be calculated from

$$
\mathrm{V}=2 \tan ^{-1} \frac{\mathrm{s}}{2 \mathrm{D}}
$$

When $\mathrm{V}$ is visual arc (minute of arc; MOA), $\mathrm{S}$ is object's height and $\mathrm{D}$ is distance between object to the eyes. According to the formula (1), When touchscreen's height is $12 \mathrm{~cm}$. and the distance from touchscreen is $40 \mathrm{~cm}$, visual arc is 1045 MOA which is set as the basic equipment. For using touchpad, Display's height is $39 \mathrm{~cm}$. and the object's distance are $130 \mathrm{~cm}, 161 \mathrm{~cm}, 249 \mathrm{~cm}, 554 \mathrm{~cm}$. then the visual arcs were calculated as $1045 \mathrm{MOA}, 845 \mathrm{MOA}, 545 \mathrm{MOA}$ and $245 \mathrm{MOA}$, respectively. By comparing to the touchscreen usage as the basic equipment, the ratio of display size are 1:1, 1:0.82, 1:0.52, and 1:0.23, respectively.

\subsection{Method}

The experiments were consisted of two sessions for each participant. The $1^{\text {st }}$ session was that the participant used the digital pen for tapping task on touchscreen and touchpad with 4 distance conditions. There were fifteen minutes break between the sessions. For the $2^{\text {nd }}$ session, participant used the digital pen for dragging task within the same conditions as tapping task. The method for tapping and dragging tasks are described as following. 


\subsubsection{Tapping task}

Tapping performance was analyzed using a one dimensional pointing task, consisting of horizontal movement between initial and target locations shown on the screen (see Fig 2). Timing began when the digital pen was lifted from the display surface, and timing stopped when the digital pen was next released (completing a second tap).

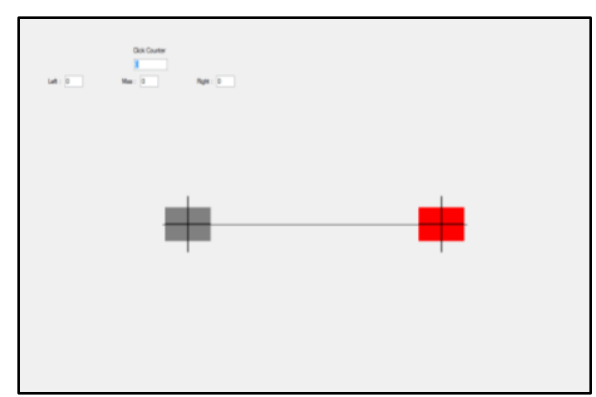

Fig. 2: The In-house software used in this experiment.

The experimental tasks were administered in five blocks of twenty selections each (ten to the left, ten to the right). All trials with in each block used the same W (width) and D (distance) of movement to give five levels of ISO 9241-9 index of difficulty [1], created from two levels of width and four levels of distance uncrossed (target was fixed at 60 pixel). ID (Index of difficulty) can be calculated from

$$
\mathrm{ID}=\log _{2} \frac{\mathrm{D}+\mathrm{W}}{\mathrm{W}}
$$

Table 1 shows combinations of $\mathrm{W}$ and $\mathrm{D}$ used to give the five levels of index of difficulty. The order of exposure to the five levels of index of difficulty was randomized.

Table 1: Width and Distance Used for the Five Levels of Index of Difficulty

\begin{tabular}{|c|c|c|c|c|c|}
\hline Width (pixel) & 240 & 480 & 960 & 480 & 1200 \\
\hline Distance (pixel) & 100 & 100 & 100 & 20 & 20 \\
\hline ID & 1.77 & 2.54 & 3.41 & 4.64 & 5.93 \\
\hline
\end{tabular}

\subsubsection{Dragging}

Dragging performance was analyzed using a multi-dimensional pointing task. Timing began when the ball was circular dragged from the display surface by digital pen, and timing stopped when the digital pen was come back to initial point (see Fig. 3).

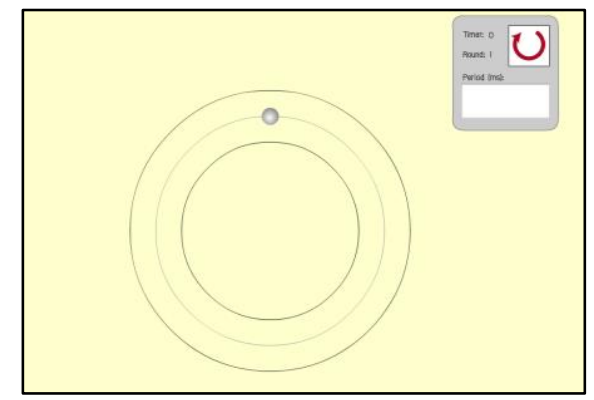

Fig. 3: The In-house software used in this experiment.

The experimental tasks were administered in five blocks of nine circular drags each. All trials with in each block used the same W (width) and R (radius) of movement to give five levels of ISO 9241-9 index of difficulty [1], created from two levels of width and four levels of radius uncrossed and ball size was fixed thirteen pixel. Index of difficulty can be calculated from

$$
\text { ID }=\frac{A}{W}=\frac{2 \pi R}{W}
$$


Table 2 shows combinations of $\mathrm{W}$ and $\mathrm{R}$ used to give the five levels of index of difficulty. The order of exposure to the five levels of index of difficulty was randomized.

Table 2: Width and Radius Used for the Five Levels of Index of Difficulty

\begin{tabular}{|c|c|c|c|c|c|}
\hline Width (pixel) & 90 & 90 & 90 & 50 & 50 \\
\hline Radius (pixel) & 100 & 200 & 300 & 200 & 250 \\
\hline ID & 6.98 & 13.97 & 20.95 & 25.14 & 31.43 \\
\hline
\end{tabular}

\section{Results}

The dependent variable of this study was MT (movement time). Effect of independent variables and their interaction on dependent variables were tested using a two-way ANOVA to find the effect of input device. In each linear predictive of visual angle were calculated between movement time and index of difficulty by simple linear regression.

\subsection{Tapping task}

Mean of movement time from analysis with using touchscreen (ratio of display size 1:1) is 0.73 (s.d. 0.26) second. Mean of movement time of using touchpad from analysis with display sizes (ratio of display size 1: $0.82: 0.52: 0.23$ ) are 1.17, 1.22, 1.27 and 1.42 second (s.d. 0.47, 0.48, 0.53 and 0.63) respectively. From ANOVA with 0.05 significant level, giving a significant interaction between input device (touchscreen and touchpad $)$ and index of difficulty $\left(\mathrm{F}_{4,1590}=109.21, \mathrm{p}<0.001\right)$, A significant interaction between display size of touchpad and index of difficulty $\left(\mathrm{F}_{12,3180}=17.88, \mathrm{p}<0.001\right)$.

Figure 4 shows results between movement time and index of difficulty of tapping task. Linear regression of performance of using touchscreen $(1: 1)$ and touchpad of various display size $(1: 0.82: 0.52: 0.23)$ are $\mathrm{MT}_{\mathrm{TS}}=0.18+0.15 \mathrm{ID}, \mathrm{MT}_{\mathrm{TP} 1}=0.17+0.27 \mathrm{ID}, \mathrm{MT}_{\mathrm{TP} 0.82}=0.17+0.29 \mathrm{ID}, \mathrm{MT}_{\mathrm{TP} 0.52}=0.18+0.30 \mathrm{ID}$ and $\mathrm{MT}_{\mathrm{TP} 0.23}=0.05+0.37 \mathrm{ID}$. There were a strong linear relationship $\left(\mathrm{R}^{2} 0.93,0.92,0.92,0.90\right.$ and 0.87$)$. The Index of Performance (IP, defined as 1/slope) is 6.67, 3.70, 3.45, 3.33 and 2.70 respectively

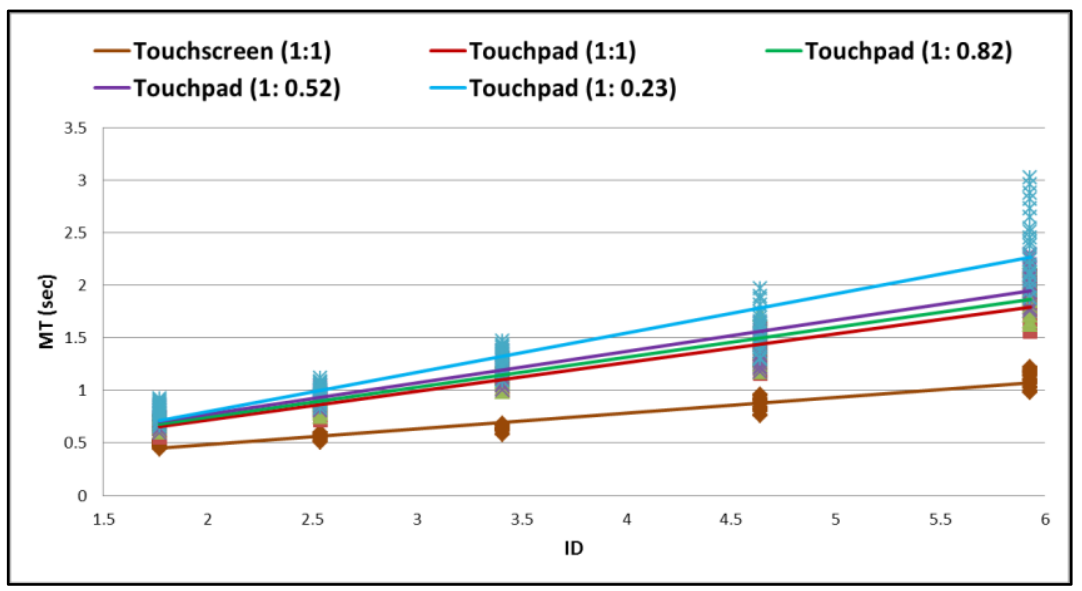

Fig. 4: Tapping task results for movement time of regression plot.

\subsection{Dragging task}

Mean of movement time from analysis with using touchscreen (ratio of display size 1:1) is 2.71 (s.d. 1.7) second. Mean of movement time of using touchpad from analysis with display sizes (ratio of display size 1 : $0.82: 0.52: 0.23$ ) are 5.17, 5.46, 5.88 and 6.06 second (s.d. 2.96, 3.34, 3.31 and 4.18) respectively. From ANOVA with 0.05 significant level, giving a significant interaction between input device (touchscreen and touchpad $)$ and index of difficulty $\left(\mathrm{F}_{4,710}=12.95, \mathrm{p}<0.001\right)$, no significant interaction between display size of touchpad and index of difficulty $\left(\mathrm{F}_{12,1420}=0.71, \mathrm{p}=0.74\right)$. Although interaction of touchpad of display size with index of difficulty was no significant. As expected, there was a significant main effect of index of difficulty $\left(\mathrm{F}_{4,1420}=214.59, \mathrm{p}<0.001\right)$ and display size $\left(\mathrm{F}_{3,1420}=147.39, \mathrm{p}<0.001\right)$.

Figure 5 shows results between movement time and index of difficulty of dragging task. Linear regression of performance of using touchscreen and touchscreen of various display size $(1: 0.82: 0.52: 0.23)$ 
are $\mathrm{MT}=0.73+0.10 \mathrm{ID}, \mathrm{MT}=0.97+0.22 \mathrm{ID}, \mathrm{MT}=0.72+0.24 \mathrm{ID}, \mathrm{MT}=0.46+0.27 \mathrm{ID}$ and $\mathrm{MT}=0.68+$ 0.27ID. There were a strong linear relationship $\left(\mathrm{R}^{2} 0.99,0.98,0.96,0.98\right.$ and 0.97$)$. The Index of Performance (IP, defined as $1 /$ slope) is $10,4.55,4.17,3.70$ and 3.70 respectively.

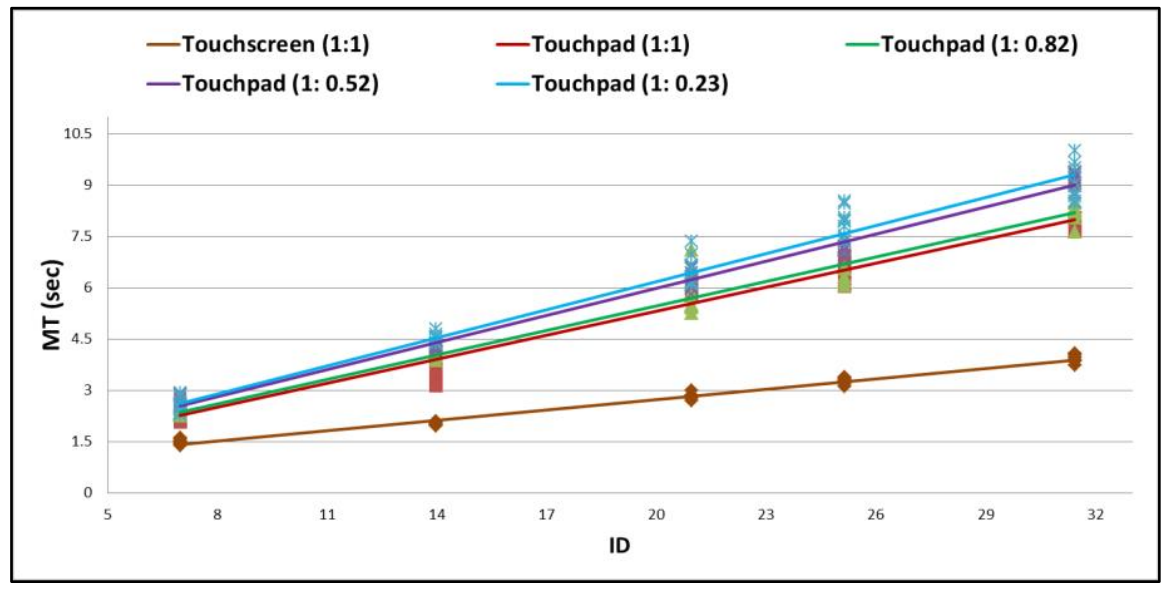

Fig. 5: Dragging task results for movement time of regression plot.

\section{Discussion and Conclusion}

We demonstrated that movement time and index of difficulty is a linear function of performance of using touchscreen and touchpad with various display size, these was strongly relationship. From this experiment, there have 2 main conclusions. First, using the touchscreen has lower movement time and higher performance than touchpad on tapping and dragging task. Second, using touchpad with the biggest display (ratio of display size 1:1) provide the lowest movement time and the highest performance and smaller are $0.82,0.52$ and 0.23 respectively provide inferior results. In other words, using the touchscreen gives the best performance. However, if touchpad is necessary, it should be big display and place it near user. In addition, this result could be one of the buying decision factor which help people or company to buying any device.

\section{Acknowledgements}

The author would like to thank to all participants.

\section{References}

[1] Kong-King Shieh and Der-Song Lee. Preferred viewing distance and screen angle of electronic paper displays. Applied Ergonomics. 2007, 38: 601-608.

[2] Kong-King Shieh. Effects of refection and polarity on LCD viewing distance. International Journal of Industrial Ergonomics. 2000, 25: 275-282

[3] Justin G. Younga, Matthieu Trudeaua, Dan Odellb, Kim Marinellib and Jack T. Dennerleina. Touch-screen tablet user configurations and case-supported tilt affect head and neck flexion angles. IOS Press 2012, 41: 91-91.

[4] Naphat Yongbunthanaphat and Phairoat ladavichitkul. Work performance comparison of holding and using tablet. IMECS, Hong Kong, 2014(2).

[5] Paul M. Fitts. The Information Capacity of the human motor system in controlling the amplitude of movement. APA Centennial. 1992, 121(3): 262-269

[6] I. Scott Mackenzie. Fitts' law as a research and design tool in human computer interaction. human computer interaction. 1992, 7: 91-139.

[7] Richard J. Jagacinski and Donald L. Monk. Fitts' law in two dimension with hand and head movements. Journal of motor behavior. 1985, 17 (1): 77-95

[8] ISO 9241-11. "Ergonomic requirements for office work with visual display terminals (VDTs)", The international organization for standardization, 1998. 